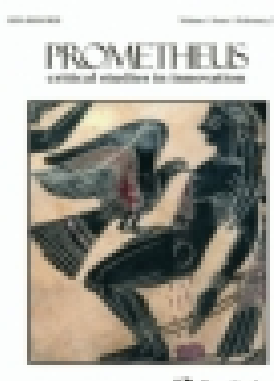

\title{
Prometheus
}

Critical Studies in Innovation

\section{A journal is a club: a new economic model for scholarly publishing}

\section{Jason Potts, John Hartley, Lucy Montgomery, Cameron Neylon \& Ellie Rennie}

To cite this article: Jason Potts, John Hartley, Lucy Montgomery, Cameron Neylon \& Ellie Rennie (2017): A journal is a club: a new economic model for scholarly publishing, Prometheus, DOI: 10.1080/08109028.2017.1386949

To link to this article: http://dx.doi.org/10.1080/08109028.2017.1386949

$$
\text { 曲 Published online: } 31 \text { Oct } 2017 .
$$

Submit your article to this journal $\square$

Q View related articles $\sqsubset$

View Crossmark data $\circlearrowright$ 


\title{
A journal is a club: a new economic model for scholarly publishing
}

\author{
Jason Potts ${ }^{\mathrm{a}}$ (D), John Hartley ${ }^{\mathrm{b}}$, Lucy Montgomery ${ }^{\mathrm{b}}$, Cameron Neylon ${ }^{\mathrm{b}}$ and Ellie Rennie \\ aschool of Economics, Marketing and Finance, RMIT University, Melbourne, Australia; ${ }^{\mathrm{b}}$ Centre for Culture \\ and Technology, Curtin University, Perth, Australia; 'School of Media and Communication, RMIT University, \\ Melbourne, Australia
}

\begin{abstract}
A new economic model for the analysis of scholarly publishing - journal publishing in particular - is proposed that draws on club theory. The standard approach builds on market failure in the private production (by research scholars) of a public good (new scholarly knowledge). In this model, publishing is communication, as the dissemination of information. But a club model views publishing differently: namely as group formation, where members form groups in order to confer externalities on each other, subject to congestion. A journal is a selfconstituted group, endeavouring to create new knowledge. In this sense, a journal is a club. The knowledge club model of a journal seeks to balance the positive externalities of a shared resource (readers, citations, referees) against the negative externalities of crowding (decreased prospect of publishing in that journal). A new economic model of a journal as a knowledge club is elaborated. We suggest some consequences for the management of journals and financial models that might be developed to support them.
\end{abstract}

\section{Economists against journals}

The existence of commercial scholarly journal publishers follows from the economics of specialisation and the division of labour. Lacy (1963) (prior to gender-neutral scholarly language) puts it like this:

Between the artist and his audience stands the medium of communication through which he must reach them: ... the broadcast networks, the publishing houses. ... Throughout history an entrepreneur of some kind has assembled the artist's audience and given him the chance to be heard (p.42).

Substitute scholar for 'artist' and other scholars for 'audience', and we have the standard modern commercial model of journal publishing. From the perspective of economic analysis, this model is predicated on the efficient organisation of the specialised capital and skills required to produce and distribute scholarly journals, and recognition that these capabilities were not efficiently possessed by scholars (or artists) as the producers and consumers of

CONTACT Jason Potts jason.potts@rmit.edu.au

Accepting editor: Stuart Macdonald 
scholarly output. The economic logic of this situation resulted in the papyrocentric business model (Harnad, 1995; where 'papyrocentric' invokes images of paper distribution, but also embraces the most developed organisational form - publishers) of a closed-access journal in which a private publishing company holds the intellectual property rights and is supplied with free content and free labour (Bergstrom, 2001; Houghton and Oppenheim, 2010).

This modern economic model, with its attendant commercial players and profits, is a departure from the original model of journals. While part of the original motivation of the first research publication in serial form - the Philosophical Transactions of the Royal Society in 1665 - was to make money (Hall, 1954), the early history of scholarly publishing is largely one of community subsidy to cover losses or breaking even. The first serials to which the name 'journal' was applied in the nineteenth century often struggled to find audiences sufficiently large to justify the printing of content of interest to professional researchers. The modern system developed only in the mid-twentieth century. The wartime and postwar expansion of public research funding and consequent expansion and globalisation of research communities were soon exploited by an entrepreneur-led proliferation of increasingly specialised journals, following the lead of Robert Maxwell's Pergamon Press (Buranyi, 2017). The small society presses, struggling to cope with growing scale, were supported and then largely supplanted by the 'Big 5' commercial presses: Elsevier (which acquired Pergamon in 1991), Wiley, Springer, Taylor \& Francis and Sage. These newly-empowered players brought an industrial approach to the publication and dissemination process, for the first time realising the benefits that these specialised capital and skills could provide by operating at a scale that was unprecedented to that date. The successful publishers grew (and consolidated to grow further) alongside a pre-Cambrian explosion and specialisation of journals to create the modern landscape in which the majority of journals is owned, controlled or at least produced by a handful of globalised companies.

But with the arrival of the computer, the internet and soon the blockchain, the economics of this model shifted (Kahin and Varian, 2000; Gans, 2000; Bergstrom and Bergstrom, 2001; Fyffe and Shulenburger, 2002; Willinsky, 2005; Houghton and Sheehan, 2009; Houghton and Oppenheim, 2010). The wide availability of desktop hardware and software enabled new capabilities among authors, and an expectation from publishers that authors would self-manage much of the layout and editing of articles. Meanwhile, technologies for storing articles (databases), discovering articles (digital object identifiers and advanced search technologies), citing and reviewing, made it easier for academics to engage with each other's work. This has forced two interrelated pressures on the extant scholarly publishing model that, taken together, suggest: (1) that it is profoundly broken (Bergstrom and Bergstrom, 2006); and (2) that a general move to an open access regime is either under way or imminent (Bergstrom and Bergstrom, 2004; Willinsky, 2006, 2009; Houghton, 2011, Armstrong, 2014; McCabe and Snyder, 2014).

First, it is no longer clear that the closed access proprietary model is at all necessary (Houghton, 2001). As the economists Conley and Wooders (2009, p.71) explain:

Open access journals have overwhelming cost advantage over commercial publishers. In addition, open access is consistent with our mission as scholars to increase and spread knowledge and also feeds our personal and professional interests much more directly. But we are still living with the system of scholarly communication we inherited from the papyrocentric era.

Second, the modern digital open access model still preserves many dysfunctional aspects of the older model of scholarly journal, including, as Bruno Frey (2003) points out, the tendency for scholars to have to prostitute themselves before editors and referees, owing to the veto 
power that referees wield and the perceived necessity of journal publication to climb career ladders. Frey proposes a series of institutional reforms in the way property rights work in scholarly publishing to mitigate this. Furthermore, as Conley (2012) editorialises, the result is bad for the scholarly community because it entrenches a model with very high rejection rates that is inordinately wasteful of 'free' scholarly resources. Conley finds this to be:

a new, and I think compelling, reason to try to reclaim scholarly communication back from commercial publishers and into the community of scholars ... (p. 7)

The twentieth-century publishing model made economic sense as outsourced specialisation, but technological change has upended that logic by dramatically lowering the cost of in-house production. The old model holds on through legacy effects and competitive 'costly signalling' of perceived prestige through selected mastheads, and has transformed into a model of monopoly exploitation. This is costly in pecuniary terms, but also in the ability of scholarly communities to develop and change publishing institutions to suit their own needs. There is now a broad consensus that the economics of scholarly publishing is broken and that a new way forward turns on exploitation of new, open access, business models (Binfield, 2013). But open access models, including hybrid models (Björk, 2012), are also proving difficult to implement, running into problems of cost, free-riding and incompatibility with extant scholarly research institutions (Neylon, 2015a).

This paper proposes a new approach to the economics of scholarly publishing that is based around the joint production and consumption of scholarly output by the scholarly community. We argue that this can be represented not as an economics of firms, markets and specialisation, but as an economics of team production and consumption in what we style 'knowledge clubs' (Hartley, 2015).

\section{The organisation of scholarly publishing}

The organisation of scholarly publishing, and indeed its broader political economy context, can usefully be understood through the narrower lens of economic analysis. The economics of publishing - not only scholarly publishing, but also quality news journalism - is usually formulated as an intermediating service in the production and consumption of a private good (information) with public good-like properties (owing to appropriability and positive externalities). Significant fixed costs in publishing, mostly attributable to capital requirements (e.g. printing presses and distribution networks) and specialist skills (e.g. typesetting, editing) pushed this model towards imperfect competition. The information economics of branded quality signalling - in authors, mastheads and presses - also tended to reinforce a winner-take-all oligopolistic market structure. Alternative institutional arrangements and experiments were created for communities and subcultures (for instance, zines) in reaction to these outcomes. For the most part, within the news media and publishing domains, these group-based efforts remained marginal players (Rennie, 2006). But when the technology of publishing changes, so does everything else (Eisenstein, 1982; Ong, 2012).

Through the nineteenth and twentieth centuries, entrepreneurial solutions were institutionally embedded within business models that furnished workable solutions to this problem. For instance, publicly-funded university libraries maintained print subscriptions to large suites of scholarly journals; or newspapers, which often held monopoly positions, cross-subsidised news journalism with classified advertising. The crisis in scholarly 
publishing in which new digital technologies run headlong into old business models, has been diagnosed as a form of disruption awaiting transformation, possibly through new models of public subsidy, or new business models, or both.

One common way to look at this is through the lens of an evolutionary industrial transformation (what Joseph Schumpeter called 'creative destruction') involving deep endogenous change in the organisational and market order. Individual academics who both produce and consume journals may worry about whether the unfolding sequence of development will eventually be characterised by a cataclysmic shakeout or by a smoother sequence of adjustments in what broadly appears to be the standard view (through the lens of the Schumpeterian industrial transformation model) of the current crisis in scholarly publishing and quality journalism.

The consequence of this narrative of disruption, whether promoted by advocates or feared (or disdained) by commercial incumbents, is that it depends on new entrepreneurs to create new markets. The narrative predicts that the Schumpeterian arrival of these new players will defeat the once-lean competitors of the mid-to-late twentieth century that have become bloated monopolists through consolidation. The new technology opportunity and entrepreneurial competition will sort this out through an industrial transformation from one technological model (the printing press and physical distribution) and one financial model (university subscriptions) to a new technological model (free online distribution of web 'native' content) and consequently new financial models (currently controversial but, according to the Schumpeterian model, surely to be determined by the market). This narrative has no place for the actual generators and consumers of value, the research author, referee, editor, and reader.

The disruption narrative sits atop a broader one of the transformation from closed private goods (the profits of publishers) into public (and therefore open) goods. The dichotomy between private and public goods is central to the rhetoric of open access advocates, whose arguments seem rooted largely in economics and the politics of public good provisioning. By the same token, it is also central to the rhetoric of traditional publisher lobbyists and traditionalists within the research community, who argue that the twentieth-century industrial model is a successful public-private partnership in which commercial entities obtain a reasonable return on private investment, and the research community receives a useable public-like good in return for its contributions. But once again, these arguments, while often referencing the 'community', usually without defining it, rarely engage with how the community is constituted, what it is contributing and what it receives in return for any specific journal.

An alternative view would be to place the community at the centre of an economic model. This would provide an alternative to both the twentieth-century broadcast/industrial model built on rational specialisation and the political argumentation based on the public-private dichotomy. Such a model would focus on the (self)-identity, contribution and benefits to a community. We believe that this form of model could provide new insight into methods by which a given community can sustain itself, supporting the re-emergence of local commons, or clubs (Harvie, 2004). Such a model may also help to refine arguments that placing the community at the centre of scholarly publishing would be a return to the eighteenth- and nineteenth-century roots of our publishing system (Fyfe et al., 2017). Our argument, therefore, is that we need to consider what it means to view scholarly publishing through the lens of club theory and the concept of a club good. 


\section{Knowledge clubs}

Club theory introduces an intermediate option between the economics of a world made entirely of individuals coordinated by markets (private goods), and a world of a collective coordinated by the state (public goods), with a third class that is based around the formation of self-interested and coordinated groups (or clubs). A club can be simply a firm that both produces and consumes. A moment's reflection on the fact that scholars both produce and consume their own product does suggest that club theory is prima facie a good approximation of scholarly publishing (Neylon, 2015, 2016). To expand this, we will need to consider who may be identified as members of this club and what the various contributions and benefits for members might be.

Traditionally, we would consider a journal to be a node that organises market relations among authors, readers and specialist publishing capabilities. This naturally leads to the presumption of outsourcing of various of these roles in a competitive market. In our new model, we see a journal as a club in which access to these services is internalised as a membership benefit. While the services might still be outsourced, in practice it can be seen that such a shift potentially has substantial political and economic consequences as to how we see the relations among players. Owners of capital and their customers are seen as service providers to communities. We have a good economic understanding of the former, but not of the latter.

Our argument here, then, elucidates a club-theoretic understanding of scholarly publishing and uses this to probe the economic and political crises challenging the current systems. We focus entirely on scholarly publishing in journals, but the general points we advance, mutatis mutandis, extend to scholarly publishing in books (Montgomery, 2015), and to quality journalism, to which we return in our Conclusion. The reason for this tight focus is that scholarly journals, particularly small society journals, present the clearest example of the knowledge club model.

The concept of a 'knowledge club' is based on the demic-diffusion model of cultural science developed by Hartley and Potts (2014). This is a coherent analytical framework built out of a synthesis of cultural studies, evolutionary economics and evolutionary biology. Its core hypothesis is that the evolutionary function of culture is to form groups, that the evolutionary function of culture-formed groups is to produce knowledge, and that the selection mechanism over those groups operates at the margin of other groups (knowledge is most intensively produced at group-boundaries, in interaction with other, competing groups). The purpose of cultural science is to naturalise the study of culture, based around the growth of knowledge, and therein to endogenise human group formation about knowledge production and consumption. This paper will not advance that model directly, but it is an application of cultural science in that it directs the analysis of the 'publishing problem' to consider group-formation dynamics. A purpose of this paper, then, is to explore this cultural science hypothesis using the (well-known and established) tools of the economics of club theory.

To reform scholarly publishing, we need to recognise that a journal is a club. A scholarly journal is neither a private good nor a public good; it is a club good (Neylon, 2015a). A journal is a publishing operation, both in production and in consumption, which is best understood - dynamically as well as statically - as a club good, meaning that the basic economics of club goods should help in making sense of the turmoil that the scholarly publishing industry is currently experiencing. 


\section{What is a club good?}

If a journal is ideally a club, what then is a club? Economic theory has a very specific answer to this question. Club goods are distinguished from private goods (where consumption is both rivalrous and excludable) and public goods (where consumption is non-rivalrous and exclusion is not possible) by being non-rivalrous (up to a congestion point) but excludable. Completing the standard four-term matrix are common pool resources, which are rivalrous but non-excludable (Ostrom, 1990). Club goods are also known as 'toll goods' (Ostrom and Ostrom, 1999) because the congestion point requires a toll for efficiency; and also as 'local public goods' (Scotchmer, 2002) because groups are often spatially organised.

The concept of a club good was introduced into economic theory by James Buchanan (1965) to recognise that the Samuelsonian division between private goods provided by markets and public goods provided by the state (Samuelson, 1954) was missing an important institutional construction in the ability of small organised groups (Olson, 1965) to come together privately to produce and consume local public goods (Sandler, 2013). Club theory is now a standard foundation of modern general equilibrium microeconomics (Berglas, 1976; Sandler and Tschirhart, 1980, 1997). Buchanan's point is that many things that were commonly portrayed as public goods (hospitals, schools, roads, swimming pools, etc.) are actually better understood as club goods.

The political economy imperative behind the club goods concept was not on the side of markets versus the state, but rather a more oblique point on the private-public continuum in that it argued for the economic efficiency of organised free individuals (groups, associations) to form groups that could self-govern to produce public goods, and that this outcome is economically superior to both market solutions and government solutions. Clubs are non-market solutions to public-good problems that rely on the ability of self-constituted groups both to self-organise and successfully to self-govern. They are non-market solutions in the technical sense that they do not rely on private property rights and price mechanisms for coordination of the club good, but rather on culture (shared understandings and norms, etc.) and governance institutions. This usually happens locally for what is increasingly recognised as evolutionary-theoretic reasons (Bowles and Gintis, 2009); hence the local public good focus on such things as health clubs, sports clubs, learning clubs (libraries), transport clubs (toll roads), and so on. But note that the internet and its digital affordances make this group formation less a spatial phenomenon and more a cultural phenomenon. This is the true implication of Anderson's 'long tail' thesis (2006): that the internet allows connection into clubs to occur without reference to ethno-territorial boundaries such that locally unviable nodes of common interest can 'club together' across cyberspace to create a community of affinity and thence a market. Locality is no longer necessarily geographic, but may be demic. Clubs, then, refer to the formation of groups of people who share a common concern, who are willing to pool their common resources and specialisation skills, and to act in concert in pursuit of shared externalities. ${ }^{1}$ This is why the economics of clubs overlaps substantially with the economics of knowledge commons (Ostrom and Hess, 2007; Frischmann et al., 2014).

In a market of individual actors, the key institutional mechanism of coordination is bilateral exchange. If both parties expect to gain such that marginal private benefit is greater than marginal private cost, then the transaction will occur and not otherwise. This principle underpins both general equilibrium theory and welfare economics. In the state or 
government, the key institutional mechanism is coercion to overcome free-riding in providing a public good such that the sum of marginal benefits for each agent is greater than the total marginal cost of public provision. This principle underpins the logic of the state and its powers. In a club, the key institutional mechanism is voluntary, culture-made, group formation such that the private benefit condition holds for a shared good. Clubs are voluntary in the language of microeconomics, but in cultural science 'voluntary' should be understood as a secondary feature of culture-made groups. Culture makes groups that are unified and bounded by shared codes, relationships, identity and meaning. The production of free individuals who are in possession of the economic rationality needed voluntarily to choose to join or form a club is a function of culture-made 'we' groups or demes. It follows that not everyone can join a club (demic outsiders); and that free individual choice is itself a product or outcome of demes, not a causal mechanism. This, first and foremost, is a socio-cultural principle, not an economic or political one. Scotchmer (2002, p.1999) explains:

Club models are models of group formation. ... The basic notion of club economies is that agents form groups to confer externalities on each other. The main source of these externalities in the original Buchanan (1965) paper are public services. Buchanan assumes that agents band together to share the cost of (excludable) public goods. Optimal sharing groups are bounded in size because of a second externality, crowding.

It is intuitive to think of a club as relating to a shared resource, such as a local swimming pool, but Scotchmer's language is precise: 'agents form groups to confer externalities on each other'. Clubs are in this sense necessarily economically rational (and politically viable) about the costs and benefits of group formation. Individuals join clubs because they expect to benefit. In the case of scholarly journals, the benefits consist of identity, where participation in the making of journal goods legitimises and validates status ( $c f$. Lave and Wenger, 1991), prestige, where citations accrue from participation as either contributor or editor (and, less successfully, as referee) via a group of readers either within the club or aspiring to join it. The 'club' is therefore not the reading public as traditionally understood (Watt, 1957/2001), but a membership that is group-recognised through shared codes and peer-based, knowledge-sharing activities.

Sandler and Tschirhart (1997) explain five key differences in the economic properties of clubs and club goods with respect to public goods:

(1) Clubs are voluntary, which means that members join clubs only where they expect a net benefit (hence for a club good, unlike a public good, the marginal rate of substitution is always positive).

(2) Clubs involve sharing, which results in crowding (or congestion). Crowding implies an upper limit of the optimal size of the club, and tolls to control crowding. There are two types of crowding - anonymous, and non-anonymous, where attributes of other members are important determinants of crowding.

(3) Clubs imply finite groups that balance at the margin externality benefits with costs associated with crowding, such that there are non-members who are excluded. This also implies an exclusion mechanism that operates at less cost than the benefits from the club.

(4) Clubs can partition over a population, enabling competition among clubs. For any population, and for a given externality and congestion function, there will exist an optimal number of clubs. 
(5) A club involves two simultaneous choices: membership size and provision level of the shared good.

A club, therefore, is a self-organising group that, in the language of microeconomics, expects to benefit from the net externalities members impose on each other, minus the costs of doing so, and organised such that an optimal club size exists (because of crowding). Clubs are voluntary (in the microeconomic rather than cultural sense); clubs involve pooling resources; and clubs involve exclusion mechanisms which are endogenous aspects of the voluntary pooling mechanisms that define the economics of a club. The implication, as Buchanan (1965) first pointed out, is that clubs have optimal sizes that are determined by technological and institutional factors. Many forms of economic organisation are clubs and, in the past 40 years, economists have explored some of their most obvious instances, as well as many less obvious forms (Scotchmer, 2002). The central implication is that scholarly journals originate within clubs. We argue that they work best when they are organised as clubs in the sense of knowledge clubs, but that there has been an unfortunate but pervasive tendency to try and push them towards operating as market goods (privately supplied by publishing firms) or as public goods (open access). But a journal is in essence a club good.

\section{The economics of knowledge production and consumption}

To identify a scholarly journal as a club, we need to connect the basic elements of club theory, which is about a group and the public good it seeks to produce and consume, to the externalities it seeks to impose and the congestion effects it will experience. The first part is simple. The group is scholars interested in a particular question or intellectual domain. This is the extension of the fabled 'invisible college' (de Solla Price, 1963) or 'imagined community' (Anderson, 1991) of scholars who pursue ideas, seeking each other out to advance a domain of knowledge in which they all have a stake. Publishing is also a crucial part of creating a scholarly identity and central to the community of a discipline (Lave and Wenger, 1991). Scholars are perhaps the most club-like of all animals, outside the military.

Less obvious are the costs and benefits of a scholarly publishing club, or knowledge club. First, a journal is a club where members confer externalities on each other. They do so in both production and consumption. The externalities here are those of reading, understanding, citing and refereeing the papers that each scholar writes. Scholarly papers are written to be read and then to be acted upon by other scholars: they are not simply consumption goods, but inputs into further scholarly production. They are both outputs and inputs. In fact, membership, communication and action in this context are all better explained as functions of culture and language than of economic exchange, which is but a means to an end, although the economic-cultural combination results in the growth of knowledge. Scholarly production and publishing differs from the publishing of novels or journalism, for example, in that the producers and the consumers are not distinct sets; rather they are an overlapping set, a club. (This raises the interesting question of whether large-scale scholarly-commercial journals, such as Nature and Science, are journals (club goods) or journalism (market-goods).) The producers of scholarly knowledge seek to impose externalities on each other. They want not just to produce papers, but to produce papers that will be read by a particular other group, possibly anonymous and unmet (as in the invisible college), but quite precisely imagined. They are producing a scholarly field, a culture-made group. 
The shared good in production is mutual attention to an idea, which is the good allegedly supplied by the publishing intermediary in the idealised form of generalised attention (Lanham, 2006). Compared with a private good, where such attention must be purchased, scholarly publishing provides attention for free (in effect, the toll). But what scholars are purchasing in their supply of content is clearly a club good: it is shared access to the benefits of other smart, like-minded scholars who are implicitly part of an open team-production exercise, itself imagined as part of a larger knowledge commons. ${ }^{2}$

From the communication perspective, congestion or crowding is a more difficult concept to grasp. Knowledge producers could reasonably be expected to prefer more readers to fewer, and higher quality readers (better informed or placed) to lower quality. The positive externality they wish to impose is knowledge, such that the fullest extent of the imagined community is not confined to disciplinary specialists, but may extend to all within a particular deme; for example, 'our' industry, city, nation, or even species. But, in practice, scholarly production does not take humanity or any other general population as its interlocutor. Most scholars actually have in mind a finite and possibly small (long tail) set of readers, even when these are people they may not know, or who may exist only in the future. Scholarly production is for a community of peers. The production and consumption realities of scholarship and science mean that there is only a finite set of people who are potential readers of the product. This is a minimum value subset of the ideal club, meaning that the publishing club experiences heterogeneous crowding (Scotchmer, 2002). The key point is that the set of potential producers and the set of incumbent consumers are the same set, although actual producers may harbour ambitions to enlarge the club by attracting previously unengaged readers. That same set of individual producers seeking knowledge dispersion is also competing to publish in the same attention space, as defined by the finite qualities of a journal, which is therefore a club.

A journal is a club because there is both shared positive externalities as the prime resource, which is new knowledge by self and others ${ }^{3}$; and there is also congestion, caused by finite attention in the readers, and in one's own time, to read, understand, comment, critique and (ultimately most important) to adopt. A scholarly journal is therefore a club in the specific senses of being: (1) voluntary; (2) non-anonymously crowded; (3) exclusive; (4) globally partitioned; and (5) rationally constructed:

(1) Voluntary means that agents within a given demic group join clubs based on a rational calculus. If the benefits are greater than the costs, then they join a club. The benefits are basically those of being read by others; the costs are those of reading and citing others, and aligning their productive purposes with the ideas of the club. Voluntary means that they make this choice based on their best assessment of career payoff and field (or deme) prosperity.

(2) Non-anonymously crowded means that agents care who else is in the club. This is not just a matter of cost sharing, as with contributing to the cost of a swimming pool, but also cost signalling, because the more prestigious or authoritative the other members, the more exclusive and therefore valuable is their membership (Potts et al., 2008). The implication from club theory economics is that we can expect differential tolls as access prices, which may sometimes be negative. ${ }^{4}$ Crowding means that each additional club member imposes a cost, and the most obvious cost in a scholarly club is access to the journal, not simply to read, but 
to access the means of production and dissemination. In a knowledge club with 30 members, each may be published, on average, once a year. In a knowledge club with 300 or 3000 members, the frequency is lower. But, of course, there is more knowledge (and prestige - up to a congestion point) in the larger club. So, on balance, there will be a trade-off on both margins.

(3) Exclusion means that a club is a mechanism for limiting the benefits of non-members, which happens quite naturally (i.e. culturally) in scholarly knowledge clubs by simple cost of access in time and language. Scholarly communities use specific language, partly for precision and partly for exclusion (Pagel, 2012). But knowledge clubs in general arrive at exclusion technologies, not all of which are technological. Indeed, many of them are social and cultural, creating boundaries in the way that languages do. It is usually easy to distinguish insiders (specialists or scientists in general) from outsiders (in expert disciplines or general populations). Hostile pranks, such as the Sokal hoax/fraud (Sturrock, 1998), demonstrate that clubs may be hoodwinked by outsiders who apparently 'speak their language' but are in fact using it to challenge their knowledge. In short, patterns of inclusion/exclusion are demic, not economic.

(4) Global partition recognises that clubs will be finite and that there will be other clubs emerging at the margin, and possibly closely related (or identical, as in public good clubs over spatial domains). But in scholarly publishing, club theory predicts that there will be many entrepreneurial opportunities at the margin of each club. In essence, club theory implies that there will also be ongoing competition, and therefore that the rent each club creates is ultimately contestable (Baumol et al., 1982). One reason for this is the accelerating number of overlapping clubs, commons and demes to which any one individual may belong (Hartley and Potts, 2014). More clubs per person leads to higher level congestion of clubs with the result that choices to participate exceed attention capacity. In scholarly publishing, this manifests itself in a proliferation of journals about a given topic (at least one from each of the Big 5 publishers). Even the most motivated and active of scholars cannot follow them all. Cultural distinctions based on territory, affinity or ideology begin to play a greater role than long tail theory would require; simultaneously, the toll exacted for entry to any one knowledge club may increasingly be resented and avoided.

(5) Rational construction means that club choice is a dual choice of membership (to join or not) and also of quantity (what level the club will supply). The level of interdependent externality (the local public good) a club chooses to offer also affects the demand for that club, which in turn affects the toll the club can charge at the margin. The point is that in general equilibrium this choice is determined simultaneously. In scholarly publishing, at least one of these variables is expectational. In consequence, knowledge clubs are speculative assets.

\section{Clubs in practice: from an idealised case towards reality}

The simplest application of the model is to the case of an idealised small scholarly society. While this is highly simplified, it is still close to the reality of some small scholarly societies in the humanities. As a starting point, we consider a society focused on a specific area of 
research publishing one journal that is made available to members. In this idealised case, the overall community of interest is clear, it is the set of members of the society. This again in our simplified case - is the same as the set of readers of the journal. Authors and reviewers are assumed to come from the membership. Members support the society through membership fees that sustain access to the means of producing the journal (this might be managed in-house or more likely contracted out). Membership is voluntary, at least in the sociological sense referred to above.

Congestion occurs in two places: in access to publication space within the journal itself (a restriction that applies mores strongly to print, but remains, albeit at a reduced level, for online journals); and in access to the attention and readership of subscribing members. Crowding is non-anonymous. Authors, and other members, care a great deal about who else is a member, who else is an author and exactly how the attention of specific readers is apportioned (Potts et al., 2008). Invitations to provide reviews and commentary, effectively offering space in the journal and a line on the curriculum vitae with lower than usual barriers to entry (i.e. less heavily refereed) show the differential tolls in play. Having the 'right' people publish in the journal adds prestige benefits for all members.

Exclusion occurs trivially through a lack of access to non-members. Less trivially, library subscriptions are almost always substantially more expensive than individual memberships. Language and shared narratives will also contribute to exclusion, but the primary mode is through exclusion from the status of member of the society, conferred only on those who, tautologically, are paid-up members. The path to membership may be more or less clear, but can be understood through the lens of legitimate peripheral participation as described by Lave and Wenger (1991), who place the issue of community at the centre of their analysis of situated learning. This reinforces the role of learning the language and identity making (and hence prestige of the community as a motivation towards identity making) as core elements of community definition and therefore exclusion.

The club is finite, both in terms of authors and society members (at least at any given point in time) and will frequently be in competition with other similar clubs at the margins. This competition has increased with the gradual disappearance (once distribution was industrialised and then digitised) of many national and local societies that flourished in a world of physical distribution and face-to-face meetings. Finally, the choice to join is clearly dependent on an expectation of what benefits will arise, both in terms of content of the journal and opportunities to publish. In principle, a member's choice to join and the club's decision to publish are both rational and dependent on each other.

\section{Adding complexity to the model}

The simple model of a society journal described above is an idealised case in which the club-like nature of all the relevant activities is clear. However, while it captures the historical roots of many of today's journals and publishers, it misses many important complexities of real cases. Perhaps the most obvious is that the financial cost of supporting most journals is today borne largely by academic libraries.

Membership of an academic institution with the relevant benefits, including access to subscription content, is another parallel club. This complicates the situation, but also in part clarifies it by separating financial contributions from others, including the effort of reviewing, authorship and editorial work, as well as the less tangible labour of constructing 
and reinforcing the club identity. Further work will be needed to define those situations which are better analysed as complex clubs, with differential membership contributions, and those situations where multiple clubs are interacting.

The second complexity is the way in which the communities of authors, readers and editorial contributors have drifted apart over the course of the twentieth century. In its extreme, we can compare cases such as Nature, where the authorship community is a miniscule part of the readership community, but also cases like PLOS ONE where a very large set of authors cannot be said to be members of an identifiably functioning community. There are clubs within the set of PLOS ONE authors and editors, and it could be argued that the authors in Nature (but not the readers) make up a (highly exclusive) club. However, the clubs of readers, authors, editors and (as illustrated by the role of academic libraries) financial supporters have drifted apart.

The first point to make is that we diagnose this as a problem, potentially a serious one. If our argument is that clubs and communities are capable of acting together to solve collective action provisioning problems in ways that are more efficient than either markets or the state, then the dissolution of clubs, or their inability to coordinate, will lead to inefficient or non-existent provisioning. Our model predicts that such journals as Nature and PLOS ONE will be found to be economically inefficient when properly analysed. Others have noted that the loss of community control over journal production appears to lead to higher costs, and therefore implicitly economic inefficiencies (Fyfe et al., 2017). We would not, however, argue that a return to economic and governance models of the eighteenth and nineteenth centuries is the solution. Rather, we need to understand how today's clubs and communities interact with each other.

Nonetheless, for all that the clear alignment of author and reader clubs has degraded, the identity of scholars remains tightly bound to choices of where (and how) to publish. Membership of an academic community may be tied to publication in specific venues and vice versa (e.g. one may not publish in Cinema Journal unless one is a member of the Society for Cinema and Media Studies), ${ }^{5}$ or it may incite restrictive practices - the kind of 'clubbiness' that, once preeminent, favours known authors in a closed circle of mutual citation.

Using the lens of club economics does not immediately solve the financial problems of scholarly publishing, but it allows us to see these problems in a new way. In particular, we argue that it provides a better way than current market models of understanding how complex contributions are generating collective goods. While the analysis of complex situations requires more work and more detailed modelling, we can already see that it offers a different diagnosis of the problems and will therefore point the way to new solutions.

\section{Understanding change}

Applying the model is one thing, showing that it is useful, ideally predictive, is quite another. A way to test this is to consider changes to our hypothetical journal from its native state as painted above. An obvious change, and one that more closely models reality for small society journals, is the expansion of authorship. What happens when authors who are not society members seek to join the club by publishing in the journal? We expect entrepreneurialism at the margins, so that changes in who is excluded are likely to be framed as experiments. We also expect differential tolls owing to non-anonymous congestion. Authors who bring prestige, or unique content that adds to the prestige of the journal, or attract new membership, 
are therefore likely to be sought out, with formal membership requirements and payments being waived (by, say, the award of an honorary fellowship or allowing a celebrity author to retain copyright over material). The calculus for the author will depend on the externalities the club provides (prestige, a particular readership, and so on).

\section{Emerging technologies and knowledge clubs}

The implications of seeing scholarly journals as club goods, as opposed to public or private goods, is that we can begin to formulate clear models, and - with emerging technologies to enact them. The club aspects of scholarly journals involve delivering prestige factors for those within the community of peer producers, as well as the practical distribution mechanisms required to ensure that mutual attention within the knowledge club is secured. In the digital environment, academic journals have retained their club-like qualities through blind peer review (even more through open review), and via editorial boards that are carefully constructed to 'send the right signals' in order to build prestige and quality assurance. However, in the case of commercial scholarly journals, those who do the work to generate these externalities for the group are outsourcing production to commercial companies, as well as the infrastructures that measure and reveal citations and impact factors.

Emerging technologies hold promise in that they may enable new forms of automated coordination that overcome the need to outsource publication, distribution and search, thereby returning these functions to the knowledge club itself. Understanding journals as club goods is useful here because it allows us to interrogate which parts of the current system we might wish to protect or enhance, and which are superfluous or detrimental to knowledge productivity.

Blockchain technology has been described as a giant distributed ledger (Swan, 2015) used for asset registry, inventory and exchange, originally built for bitcoin but increasingly applied to other systems, including legal contracts and identity verification. The importance of blockchain technology is that it can achieve trust (a major club benefit) in a trustless (open network) internet through encryption and automation. According to Buterin (2015), blockchain is not about enforcing one set of rules, but 'creating the freedom to create a new mechanism with a new ruleset extremely quickly and pushing it out'. Blockchain technology can thereby provide a technical layer upon which decentralised governance systems can run. In the case of scholarly publishing, blockchain could be used to resolve current weaknesses in the system, including securing peer review and generating trusted and open citation metrics. For instance, blockchain technology can transform such attributes as citations into token-like objects, resulting in trustworthy open metrics as opposed to proprietary database systems. A token-like system could also shift what is currently volunteer-based labour into an incentive-compatible system that rewards referees and editors, not just authors. For instance, refereeing journal articles might result in micropayments (either monetary or reputation-based) that accrue to those who perform such tasks, providing transparency of labour on the production side and encouraging those within the club to perform tasks that, under current conditions, they are increasingly reluctant to perform (to such an extent that Big 5 publishers now routinely offer incentives to referees, such as discounted prices on their products). Platforms such as Steem, experimental at the time of writing, work on similar systems. ${ }^{6}$ 
Such technologies could also be used to authenticate academic works that have been through the process of peer review and editorial acceptance. If a scholarly work has been assigned the value of 'accepted' on the blockchain, then the need for physical or digital journal artefacts diminishes. It is foreseeable that authors could distribute a work through whatever means they feel is appropriate (for instance, a university repository) and be assured that it possesses identifiers that prove the knowledge club (journal) has accepted the work. These same identifiers could be used for searching, effectively bundling knowledge club outputs from across a distributed system such that the knowledge club's ends (to form knowledge-making communities) are reprioritised over its means (journals as consumer products). The journal itself may not be necessary, reducing or eliminating production costs altogether. This would mirror the current experience of many student readers who have no interest in the journal but scour individual papers for suitable quotations. For scholars, however, this may present a more serious challenge, further individualising and commodifying the production of knowledge (individual authors and papers, detached from clubs and groups), and fragmenting or decomposing the culture of scholarship. Finding the best model of distributed governance for journals is therefore an important task. Different rewards for different kinds of contributions is one possibility; rewarding collaboration, interdisciplinary research, the re-testing of results, and other forms of club consolidation are just some possibilities. A question for further research and a problem for cultural science, then, is how to preserve the club (the 'end') while reducing the cost of the good (the 'means'). Or should publishers transform their own business model to provide a service for knowledge clubs, supporting the formation of new clubs rather than relying on individual competitiveness among authors?

\section{Conclusion: knowledge clubs evolve}

Scholarly publishing works best as a club good. This matters to economics because the standard diagnosis is that publishing is a private good with public good aspects, and is thus analysed through the lens of information economics and market failure. The consequence is a misdiagnosis: the crisis in scholarly publishing may not, in fact, be an industrial transformation with complex consequences. If it is instead a process of club evolution, then scholars themselves will need to develop new and better governance models to maintain the productive power of knowledge-making communities, rather than the prestige of restrictive titles (e.g. Frey, 2003; Gans, 2017).

Knowledge clubs are communities with governance structures that evolve through differential variation and selection (largely through entry by new scholars, and exit as scholars leave) in the context of the institutional structure of clubs (through which scholars interact, in part through the mechanism of publishing). The arguments of Karl Popper (1963) and Thomas Kuhn (1970) on the nature and structure of scientific revolutions reinforce this clublike aspect of the dynamics of science, as does the history of important discipline-forming groups, including Austrian economics (Dekker, 2016) and empirical science itself (Shirky, 2010). Modelling scholarly publishing as a club good starts by focusing on the way in which scholarly output is produced and consumed. Producers of knowledge seek to interact with other producers whose ideas they will consume as a fuzzy set of that same knowledge. The gain from such club formation is the ability to confer externalities on each other in the form of readership, critique and understanding, and is set against the congestion costs imposed, 
along with the negative aspects of 'clubbiness' that may set in once exclusivity (status) is tradable in a social network market. The crowding costs are access to those same journal slots, which increases the larger the club. The general equilibrium logic is that there will be an optimal number of scholarly clubs (journals) and an optimal allocation of scholars over clubs. There will be a finite number of clubs, and each club will contain a finite number of scholars, and each scholar may be a member of several or many clubs. Club theory is the natural language of the economic analysis of scholarly publishing.

However, knowledge is expansive and dynamic and not a zero sum game. As the cultural science approach demonstrates, knowledge is cultural as well as economic and co-evolves with communication technologies. Thus, 'general equilibrium' and 'finite number' are contextual terms in a larger frame of reference applying only to incumbent players (already certified scholars). But communications technologies, such as the internet - the very technologies that have undermined existing business models - are also generating new kinds of knowledge club beyond the purview and scope of scholarly communication as presently constituted. There remains an external creative destructive competitive pressure on scholarly institutions overall, be they epistemological (disciplines), spatial (universities), local (specialist knowledge clubs) or institutional (such publishers as university presses). An implication is that scholars themselves need to attend to the dynamics of club formation, which may already be much more advanced in informal DIY, start-up and entrepreneurial environments than in the papyrocentric universe of peer review journals. Creative destruction is at hand. Publishers should be concerned, but those who should worry most are those who produce and consume knowledge without really understanding the value of knowledge clubs and commons. If a journal is a club, we should be creating new types of journals that nurture the dynamic formation of new knowledge clubs.

\section{Notes}

1. This is closely related to the concept of a community of practice (Amin and Roberts, 2008).

2. We mean this in the sense both of open innovation economics (models of open knowledge production) (von Hippel, 2005; Chesbrough, 2003), and also of team production (Alchian and Demsetz, 1972). An 'open team' is a concept that is separately defined in microeconomics, but not in its conjunction ( $c f$. an innovation commons).

3. Scholarly publishing has the same logic as a research department in the sense of organising itself into problem-domain themes - a point that has been made by Kling et al. (2002) in reference to the efficacy of the underlying guild model of scientific production and publishing.

4. For example, invited articles with the implication of lower refereeing hurdles, or free submission to journals normally requiring article processing charges.

5. For Cinema Journal see http://www.cmstudies.org/?page=cinema_journal; and for the Journal of Finance see http://onlinelibrary.wiley.com/journal/10.1111/(ISSN)1540-6261/homepage/ Society.html, where 'Membership in the Association is ... available only through written application'.

6. https://steem.io/.

\section{Disclosure statement}

John Hartley is Editor of the International Journal of Cultural Studies (SAGE) and Cultural Science Journal (Open Access: http://cultural-science.org/journal/index.php/culturalscience/issue/archive). Cameron Neylon was employed at PLOS as Director of Advocacy from 2012-2015. All of the information discussed in the paper is in the public domain. 


\section{Funding}

This work was supported by Australian Research Council [grant number FT120100509]

\section{ORCID}

Jason Potts (D) http://orcid.org/0000-0003-1468-870X

\section{References}

Alchian, A. and Demsetz, H. (1972) 'Production, information costs, and economic organization', American Economic Review, 62, 5, pp.777-95.

Amin, A. and Roberts, J. (2008) 'Knowing in action: beyond communities of practice', Research Policy, 37, 2, pp.353-69.

Anderson, B. (1991) Imagined Communities, Verso, London.

Anderson, C. (2006) The Long Tail: Why the Future of Business Is Selling Less of More, Hyperion Books, New York.

Armstrong, M. (2014) Opening Access to Research, working paper, Department of Economics, University of Oxford, April.

Baumol, W., Panzar, J. and Willig, R. (1982) Contestable Markets and the Theory of Industrial Structure, Harcourt Brace, New York.

Berglas, E. (1976) 'On the theory of clubs', American Economic Review, 66, pp.116-21.

Bergstrom, T. (2001) 'Free labour for costly journals', Journal of Economic Perspectives, 15, pp.183-98.

Bergstrom, C. and Bergstrom, T. (2001) 'The economics of scholarly journal publishing', available from http://octavia.zoology.washington.edu/publishing/.

Bergstrom, C. and Bergstrom, T. (2004) 'The costs and benefits of library site licenses to academic journals', Proceedings of the National Academy of Science, 101, pp.897-902.

Bergstrom, C. and Bergstrom, T. (2006) 'The economics of ecology journals', Frontiers of Ecology and the Environment, 4, 9, pp.488-95.

Binfield, P. (2013) 'Open access mega-journals', available from http://creativecommons.org. nz/2013/10/open-access-megajournals-have-they-changed-everything/ [accessed January 2016].

Björk, B. (2012) 'The hybrid model for open access publication of scholarly articles: a failed experiment?', Journal of the American Society for Information Science and Technology, 63, 8, pp.1496-504.

Bowles, S. and Gintis, H. (2009) A Cooperative Species, Cambridge University Press, Cambridge.

Buchanan, J. (1965) 'An economic theory of clubs', Economica, 32, 125, pp.1-14.

Buranyi, S. (2017) 'Is the staggeringly profitable business of scientific publishing bad for science?', Guardian, available from https://www.theguardian.com/science/2017/jun/27/profitable-businessscientific-publishing-bad-for-science [accessed June 27].

Buterin, V. (2015) 'Visions part I: the value of blockchain technology', available from https://blog. ethereum.org/2015/04/13/visions-part-1-the-value-of-blockchain-technology/ [accessed March 2016].

Chesbrough, H. (2003) Open Innovation, Harvard Business School Press, Cambridge, MA.

Conley, J. (2012) 'Low acceptance rates, commercial publishing, and the future of scholarly communication', Economics Bulletin, 32, 4, p.A37.

Conley, J. and Wooders, M. (2009) "But what have you done for me lately?" Commercial publishing, scholarly communication and open access', Economic Analysis \& Policy, 39, 1, pp.71-87.

De Solla Price, D. (1963) Big Science, Columbia University Press, New York, Little Science.

Dekker, E. (2016) The Viennese Students of Civilization: The Meaning and Context of Austrian Economics Reconsidered, Cambridge University Press, Cambridge.

Eisenstein, E. (1982) The Printing Press as an Agent of Change, Cambridge University Press, Cambridge. Frey, B. (2003) 'Publishing as prostitution: choosing between one' own ideas and academic success', Public Choice, 116, pp.205-23. 
Frischmann, B., Madison, M. and Strandburg, K. (2014) Governing Knowledge Commons, Oxford University Press, Oxford.

Fyfe, A., Coate, K., Curry, S., Lawson, S., Moxham, N. and Røstvik, C. (2017) Untangling Academic Publishing: a History of the Relationship between Commercial Interests, Academic Prestige and the Circulation of Research, Zenodo, doi:10.5281/zenodo.546100.

Fyffe, R. and Shulenburger, D. (2002) 'Economics as if science mattered: the BioOne business model and the transformation of scholarly publishing, Library Collections, Acquisitions, and Technical Services, 26, 3, pp.231-39.

Gans, J. (ed.) (2000) Publishing Economics: Analyses of the Academic Journal Market in Economics, Edward Elgar, Cheltenham.

Gans, J. (2017) Scholarly Publishing and its Discontents, Core Economics Publishing, Melbourne.

Hall, A. (1954) The Scientific Revolution: 1500-1800, Longmans, Green \& Co., New York.

Harnad, S. (1995) 'The post-Gutenberg galaxy: how to get there from here', Information Society, 11, 4, pp.285-91.

Hartley, J. (2015) 'Public intellectuals: La lutte continue?', Media International Australia, 156, pp.108-22.

Hartley, J. and Potts, J. (2014) Cultural Science: A Natural History of Stories, Demes, Knowledge and Innovation, Bloomsbury, London.

Harvie, D. (2004) 'Commons and communities in the university: some notes and some examples' Commoner, available from http://www.commoner.org.uk/08harvie.pdf.

Houghton, J. (2001) 'Crisis and transition: the economics of scholarly communication', Learned Publishing, 14, 3, pp.167-76.

Houghton, J. (2011) 'The costs and potential benefits of alternative scholarly publishing models', Information Research, 16, p.1.

Houghton, J. and Oppenheim, C. (2010) 'The economic implications of alternative publishing models', Prometheus, 28, 1, pp.41-54.

Houghton, J. and Sheehan, P. (2009) 'Estimating the potential impacts of open access to research findings', Economic Analysis and Policy, 39, 1, pp.127-42.

Kahin, B. and Varian, H. (eds) (2000) Internet Publishing and Beyond: the Economics of Digital Information and Intellectual Property, MIT Press, Cambridge MA.

Kling, R., Spector, L. and McKim, G. (2002) 'Locally controlled scholarly publishing via the internet: the guild model', Proceedings of the American Society for Information Science and Technology, 39, 1, pp.228-38.

Kuhn, T. (1970) The Structure of Scientific Revolutions, University of Chicago Press, Chicago.

Lacy, D. (1963) 'The economics of publishing', Daedalus, 92, 3, pp.42-62.

Lanham, R. (2006) The Economics of Attention, Chicago University Press, Chicago.

Lave, J. and Wenger, E. (1991) Situated Learning: Legitimate Peripheral Participation, Cambridge University Press, Cambridge.

McCabe, M. and Snyder, C. (2014) 'The economics of open-access journals', available from SSRN: http://ssrn.com/abstract=914525.

Montgomery, L. (2015) 'Knowledge Unlatched: a global library consortium model for funding open access scholarly books' in Hartley, J. and Qu, W. (eds) Re-Orientation: Trans-cultural, Trans-lingual Transmedia: Studies in Narrative, Language, Identity and Knowledge, Fudan University Press, Shanghai, pp.234-55.

Neylon, C. (2015) 'The limits on open: why knowledge is not a public good: and what to do about it', available from http://cameronneylon.net/blog/the-limits-on-open-why-knowledge-is-not-apublic-good-and-what-to-do-about-it/.

Neylon, C. (2016) 'Communities need journals', Notes and Records, 70, 4, pp.383-5.

Olson, M. (1965) The Logic of Collective Action, Harvard University Press, Cambridge MA.

Ong, W. (2012) Orality and Literacy: Technologizing the Word, Routledge, Abingdon.

Ostrom, E. (1990) Governing the Commons, Cambridge University Press, Cambridge.

Ostrom, E. and Hess, C. (eds) (2007) Understanding Knowledge as a Commons: From Theory to Practice, Edward Elgar, Cheltenham. 
Ostrom, E. and Ostrom, V. (1999) 'Public goods and public choices' in McGinnis, M. (ed.) Polycentricity and Local Public Economics, Michigan University Press, Ann Arbour, pp.75-98.

Pagel, M. (2012) Wired for Culture, Norton, New York.

Popper, K. (1963) Conjectures and Refutations, University of Chicago Press, Chicago.

Potts, J., Cunningham, S., Hartley, J. and Ormerod, P. (2008) 'Social network markets: a new definition of the creative industries', Journal of Cultural Economics, 32, 3, pp.167-85.

Rennie, E. (2006) Community Media: A Global Introduction, Rowman \& Littlefield, Oxford.

Samuelson, P. (1954) 'The pure theory of public expenditure', Review of Economics and Statistics, 36, 4, pp.387-9.

Sandler, T. (2013) 'Buchanan clubs', Constitutional Political Economy, 24, 4, pp.265-84.

Sandler, T. and Tschirhart, J. (1980) 'The economic theory of clubs: an evaluative survey', Journal of Economic Literature, 18, pp.1481-521.

Sandler, T. and Tschirhart, J. (1997) 'Club theory: thirty years later', Public Choice, 93, pp.335-55.

Scotchmer, S. (2002) 'Local public goods and clubs' in Auerbach, A. and Feldstein, M. (eds) Handbook of Public Economics, 4, pp.1998-2042.

Shirky, C. (2010) 'The shock of inclusion', Edge, available from https://www.edge.org/responsedetail/11609.

Sturrock, J. (1998) 'Le pauvre Sokal', London Review of Books, 20, 14, pp.8-9.

Swan, M. (2015) Blockchain: Blueprint for a New Economy, O'Reilly Media, Sebastopol.

Von Hippel, E. (2005) Democratizing Innovation, MIT Press, Cambridge MA.

Watt, I. (1957/2001) The Rise of the Novel, University of California Press, Berkeley.

Willinsky, J. (2005) 'Scholarly associations and the economic viability of open access publishing', Open Journal System Demonstration Journal, 1, p.1.

Willinsky, J. (2006) The Access Principle: the Case for Open Access to Research and Scholarship, MIT Press, Cambridge MA.

Willinsky, J. (2009) 'The stratified economics of open access', Information Economics and Policy, 39, 1, pp.53-70. 